Agricultural research strategy

Resource Allocation and Productivity in National and International Agricultural Research. Edited by T. M. Arndt, D. G. Dalrymple and V. W. Ruttan. Pp. 617. (University of Minnesota Press : Minneapolis, 1977.) \$25.

CAN science be justified in quantitative economic terms? If no convincing reply, one way or the other, has yet been given, some progress has been made towards the economic analysis of one area, namely research carried out to create new agricultural technology. This research is mostly publicly funded and so has identifiable expenditures; moreover, it generates evident benefits, such as increases in crop yields, which can be quantified. It is virtually indisputable that increases in food supply must improve the welfare of mankind.

Griliches's pioneering study of hybrid maize first provided a methodology, and by 1969 it was possible to hold a symposium on Resource Allocation in Agricultural Research (ed. W. L. Fishel, University of Minnesota Press, 1971). We now have the Airlie House conference, which takes account of developments since then.

The book consists of 29 papers which were re-written, and edited, after the symposium. This has blunted the sharp edge of controversy, and it might have been interesting to have included one review paper by a devil's advocate. An issue he might have pursued is the gap which exists between theoreticians (especially model builders) and those needing practical techniques.

Even with careful editing, it could hardly be expected that a coherent synthesis of the whole field would emerge, but the papers provide valuable background on several particular aspects. These are: descriptions of agricultural research institutions, especially those for developing countries, economic analysis of national and international agricultural research systems, and methods of planning and organising agricultural research. It may be mentioned that a good account of the conference is available free as a seminar report from the Agricultural Development Council, New York.

Although all the social implications of technical change in agriculture could not be fully explored, the conference has importance as a deliberate attempt at closer collaboration between social and other scientists, an initiative which is to be welcomed.
The main theme was the "social rate of return on agricultural research", a concept deriving from Griliches. It is well known, even notorious, that such calculations lead to very high numbers, but this raises some queries. Why is agricultural research so productive? If so, why do governments not invest more in it? And if subjective planning methods have proved so successful, why seek to replace them by more elaborate, but still untried, methods?

Although a consensus at the conference did not accept it, the suggestion was made that the rate of return is an inappropriate planning indicator, since it implies that there are no constraints on other factors such as land, labour, energy, capital, imports, and so on. Viewed thus, the high rates of return are only artefacts, and the way

\section{Free-living and parasitic Protozoa}

Protozoa. By A. Westphal (in collaboration with $\mathrm{H}$. Muhlpfordt). (Translated from the German by W. H. R. Lumsden and G. A. Targett.) Pp. 325. (Blackie: Glasgow and London, 1976.) $£ 9.90$.

WITH a few notable exceptions one rarely finds modern texts which encompass both free-living and parasitic Protozoa. Any new publications in the field are therefore welcomed. This is a book of high technical quality. It is profusely illustrated with delightful line drawings which, combined with a use of clear and varied typeface in the text, produces a book of immediate visual impact.

From the outset the author has imposed well defined limits on the objectives of this book. In the preface he states "it is not intended to be, and cannot be, anything more than an introduction to protozoology". To this end, the book is divided into three sections: the first, which occupies half the text, deals with the taxonomy of the phylum; the second describes the myriad cell organelles found in these organisms; the final section briefly discusses the ecology of the Protozoa.

In the taxonomic section the wealth of illustration excels. Each class is described in the text concisely, although frequently at the expense of clarity. The description is followed by diagrams showing the range of morphology and life cycles in the relevant organisms. This format does however become wearing on the reader when the illustrations are referred to frequently in the text. The inclusion of a systematic key could then be open for a different and more realistic presentation to governments of the important contribution which agricultural research can make to national economies.

It is possible, therefore, that the Airlie House conference will prove to be a watershed. Griliches's original study has been prolific, but we need to subject the methodology to close scrutiny and to consider developing improved procedures. This could well be the theme for another conference; meanwhile, this volume provides economists and those concerned in agricultural research strategy with a useful source on current thinking.

W. S. Wise

W. S. Wise is Head of the Programmes Section with the Agricultural Research Council, London, UK.

would have increased the practical value of this book.

The description of the cell biology of the Protozoa provides an insight into the amazing complexity of the subcelfular morphology achieved in this 'simple' group of organisms. It is unfortunate that the reproduction of the electron micrographs does not match the quality of the line diagrams. Here, as elsewhere in the book, there is a dogmatic tenacity for a scientifically accurate text rather than a simple and readable one. It is inevitable in such a wide ranging introductory book that that author's necessity for generalisation introduces errors in specific instances. Moreover, the description of meiosis and mitosis does not match the standard set by the remainder of the text, and could well have been omitted.

The final chapter of the book, on the Protozoa and their environment, briefly examines the distribution of some common free-living Protozoa and provides a more expansive and highly readable section of the impact of the principle protozoan parasites of man and his domestic animals.

It is inevitable that this not inexpensive book be compared with Grell's Protozoology, a book of similar technical layout and scientific interest, which, although much more expensive, covers all aspects in great depth. Although the latter will certainly be the choice of the committed protozoologist, Westphal's text is one that could be considered for many undergraduate applications.

R. E. Sinden

$R$. E. Sinden is Lecturer in Zoology in the Department of Zoology and Applied Entomology at Imperial College Field Station, Ascot, UK. He is Secretary of the British Section of the Society of Protozoology. 